
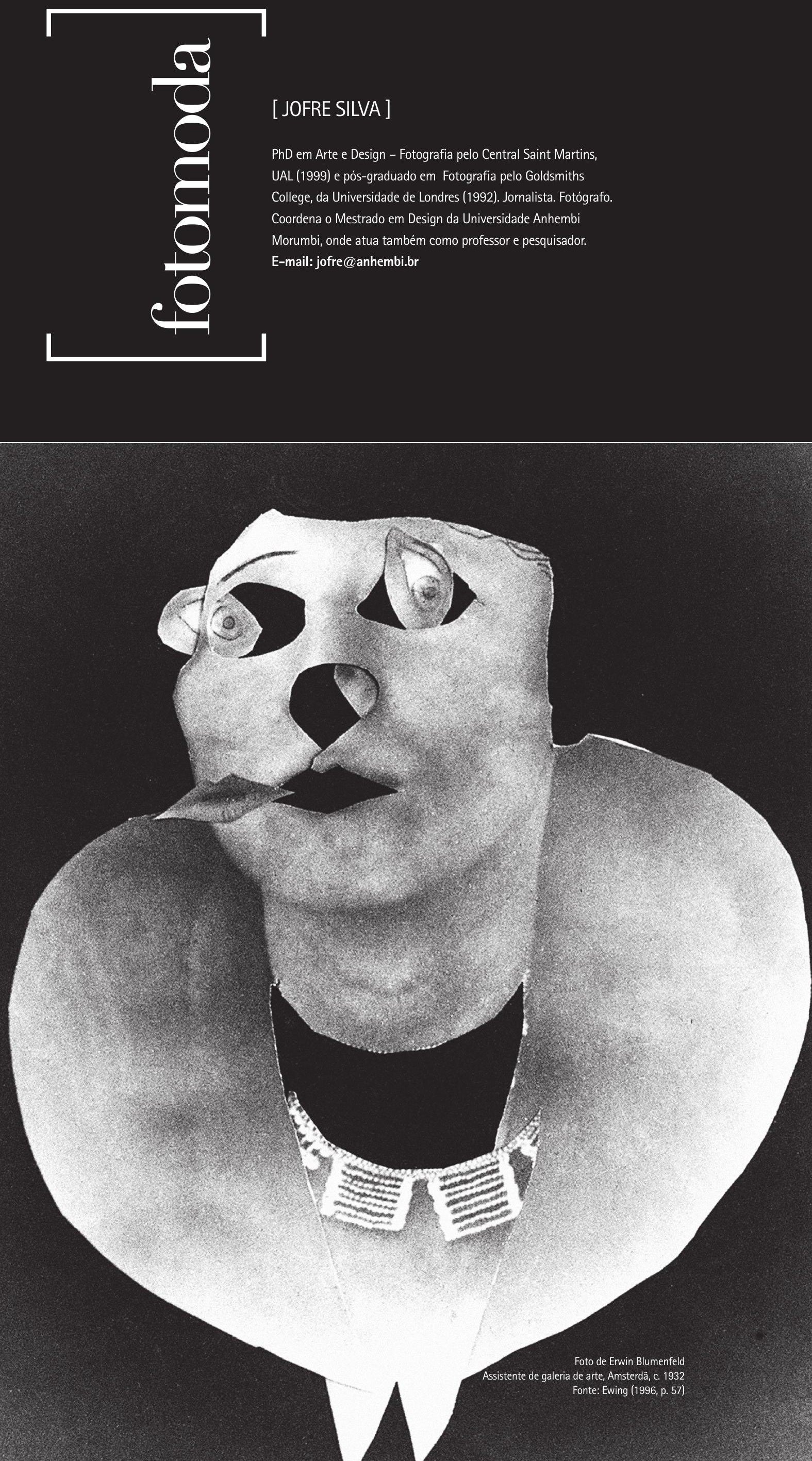


\section{Instinto pela beleza}

Erwin Blumenfeld fotografava a beleza da mulher, ignorando o evidente e o imediatamente reconhecivel. Procurava enfocar sentimentos e emoções impenetráveis e misteriosos. Na tentativa de discutir a complexidade do corpo humano, usava a fotografia para descobrir e revelar o belo, muitas vezes escondido e protegido no interior da pessoa. Assim, rostos e corpos são esticados, espremidos, multiplicados, fragmentados e suavizados. A proposta conceitual de Blumenfeld é ambiciosa. Fica impossível ignorar o impacto de suas soluções plásticas, descaradamente poéticas.

Blumenfeld declarava ter fetiche por olhos, cabelos, seios e bocas. Quando fotografava pessoas, evitava definir suas fotos como retratos, pois não tinha interesse em registrar uma personalidade única. Ao preferir a figura anônima, sem individualizar, a sua intenção era liberar o objeto de suas limitações físicas e espaciais, substituindo o sentimento de distância pela separação subjetiva, instável e imprecisa. Além da moda, produziu também imagens com cenas de rua, parques e jardins.

\section{Força gráfica}

0 vigor do apelo visual de suas imagens comerciais, especialmente no campo da moda, costuma ser identificado como fruto de um diálogo próximo, mantido com as artes plásticas. Na verdade, o seu interesse inicial pela tecnologia fotográfica coincidiu com suas outras experiências criativas como, por exemplo, a colagem, o desenho e a pintura. Assim, na contramão do perfil profissional da época, Blumenfeld alterava, cortava e aplicava diferentes interferências sobre as suas fotos. 0 sucesso de seus projetos era obtido por sua insistência em adotar um método de trabalho totalmente experimental. Sua obra costuma ser considerada na história da fotografia como a mais gráfica de todas.

Enquanto morava em Berlim, onde nasceu em 1897, Blumenfeld adotou uma posição crítica ao racionalismo excessivo do modelo burguês da época e desenvolveu uma percepção mais observadora, valorizando o instinto e o poder do inconsciente. Atraído pela irreverência, ousadia e ironia do movimento dadaísta, realizou vários estudos bem-humorados sobre a deterioração dos valores sociais vivenciados. Nesse período, sua produção visual abordou temas relacionados ao sofrimento humano,

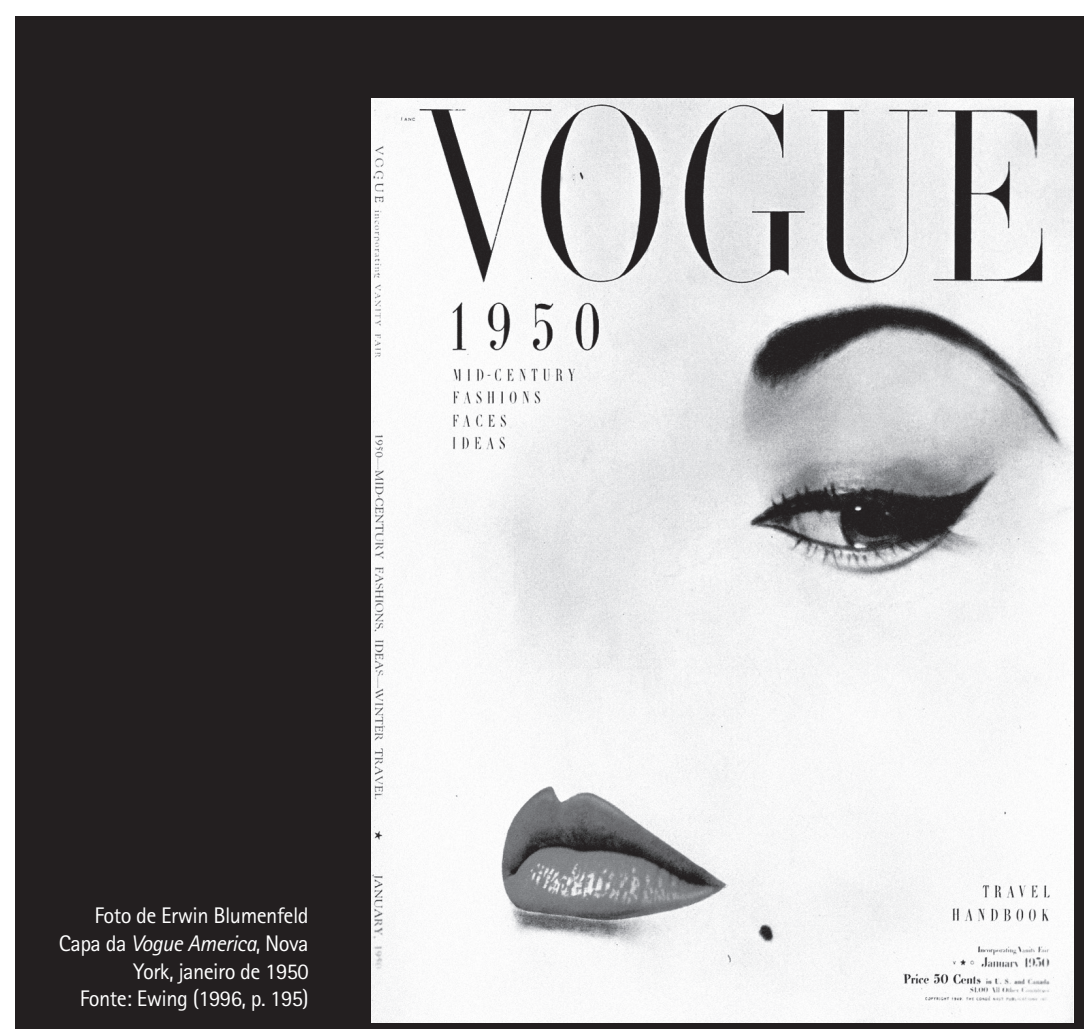


guerra, religião e misticismo. Em suas colagens, trabalhou com fragmentos de fotos, mapas, cartas, reproduções de pinturas, selos, jornais e revistas, acrescentando, às vezes, pequenos desenhos em nanquim, aquarela ou pastel. Na pintura, cenas domésticas, natureza-morta e retratos da própria família.

A mudança para os Estados Unidos, motivada pela pressão econômica e pela guerra na Europa, quando foi preso e passou por quatro campos de concentração, possibilitou conquistas profissionais de grande impacto para a trajetória de Blumenfeld. Aclamado pela crítica do jornal The New York Times como um dos mais prolíficos e publicados fotógrafos de moda do século $X X$, adquiriu fama de ser o melhor e o mais caro do mercado publicitário americano. Desenvolveu projetos para vários clientes, como Vogue, Harper's Bazaar, Cosmopolitan, Helena Rubinstein e Life.

0 desejo por variedades no período pós-guerra trouxe prosperidade para as revistas e demais esferas do setor publicitário. A demanda criou pressão para a busca contínua do novo, alimentando expectativas por imagens cada vez mais atrativas e impressionantes. Blumenfeld concentrou sua produção em ambientes de estúdio e não cobriu desfiles de moda, como tantos outros profissionais da época. No tratamento da tecnologia, evitava seguir as orientações fornecidas pelos fabricantes de produtos da indústria fotográfica. Apreciava, por exemplo, a ideia de ter um filme danificado por meio de uma revelação incorreta. Porém, mantinha controle absoluto do momento de registro da luz. Cuidava pessoalmente da preparação do estúdio, e seus modelos tinham muito pouco espaço para movimentos espontâneos e improvisados. Programava rigidamente os gestos e as poses fotografadas.

0 sucesso não alterou as motivações básicas de sua fotografia. Blumenfeld preservou a preocupação em separar o projeto comercial do pessoal, mantendo seu interesse por temas como nus, paisagens e arquitetura. Anos mais tarde, quando percebeu que a fotografia de moda não era mais suficiente como um espaço de expressão, começou a empregar a palavra. Deixou prosa, poesia, e um pouco antes de sua morte, em 1969, concluiu a redação de sua biografia. Indiscutivelmente, sua obra consolidou a fotografia de moda como um importante espaço de atuação profissional na cultura visual ocidental das últimas décadas. Irving Penn e William Klein estão, por exemplo, entre tantos outros fotógrafos que reconhecem a genialidade e a inventividade gráfica do imaginário fetichista de Blumenfeld.

\section{REFERÊNCIA}

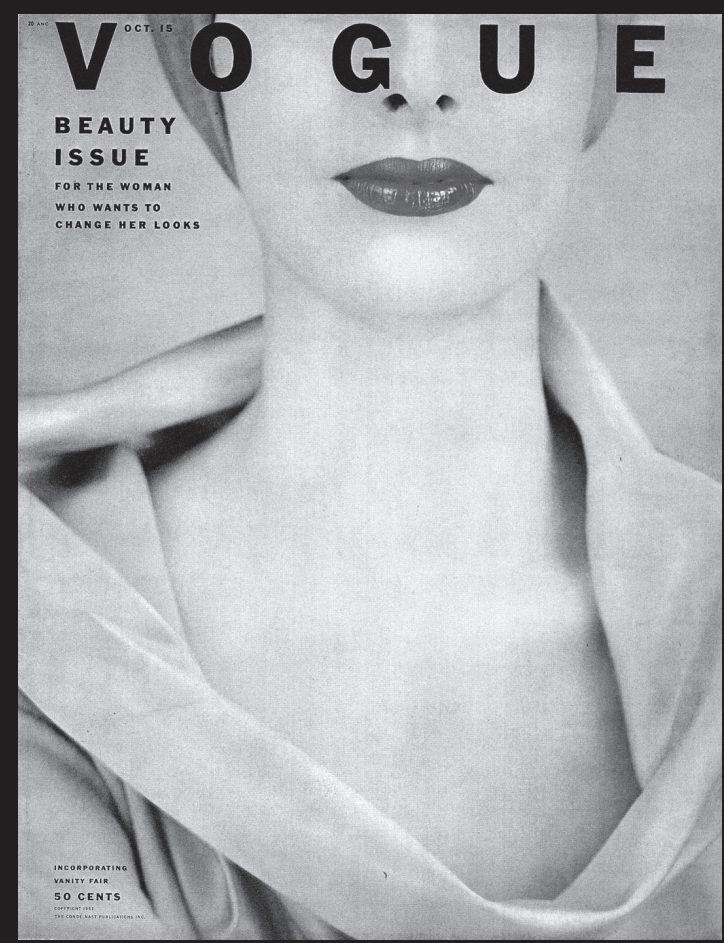

